\title{
PENJADWALAN PENGGANTIAN KOMPONEN GAS COMPRESORUNIT C WAUKESHA L7042 GSI DENGAN METODE AGE REPLACEMENT (PT. PERTAMINA EP ASSET TAMBUN FIELD)
}

\author{
Murwan Widyantoro ${ }^{1}$, Rifda Ilahy Rosihan ${ }^{2}$, Warniningsih $^{3}$ \\ Fakultas Teknik Universitas Bhayangkara Jakarta Raya \\ Email: murwan@dsn.ubharajaya.ac.id ${ }^{1}$; \\ rifda.ilahy@dsn.ubharajaya.ac.id²;warningsttl@yahoo.com
}

\begin{abstract}
ABSTRAK
Pemeliharaan (maintenance) merupakan aktivitas menjaga sistem peralatan dan mesin selalu tetap konsisten dalam proses produksi. Secara umum, masalah pemeliharaan sering terabaikan sehingga kegiatan pemeliharaan tidak teratur, yang pada akhirnya apabila mesin dan peralatan mengalami kerusakan dapat mempengaruhi kapasitas produksi. Diperlukan perencanaan perawatan mesin yang terjadwal (preventive maintenance) dalam hal ini penggantian pencegahan (preventive replacement) komponen mesin untuk mengurangi kerusakan mesin secara mendadak (failure maintenance). PT. Pertamina EP Asset 3 Tambun Field merupakan salah satu perusahaan yang bergerak di industry perminyakan. PT. Pertamina EP Asset 3 Tambun Field memiliki dua komponen yang sering mengalami kerusakan sehingga mengakibatkan proses terganggu. Dua komponen tersebut terdapat merupakan komponen pada Gas Compressor, yaitu komponen Connecting Rods dan Crankcase. Tujuan dilakukannya penelitian ini adalah mengetahui komponen kritis dari Gas Compressor pada PT. Pertamina EP Asset 3 Tambun Field, menentukan interval preventive maintenance untuk komponen kritis dengan menggunakan metode Age replacement.
\end{abstract}

Kata Kunci : Age Replacement, Failure maintenance, Gas Compressor, Pemeliharaan, Preventive maintenance.

\section{SCHEDULE FOR REPLACEMENT OF COMPONENTS GAS COMPRESORUNIT C WAUKESHA L7042 GSI WITH AGE REPLACEMENT METHOD (PT. PERTAMINA EP ASSET TAMBUN FIELD)}

\begin{abstract}
Maintenance is an activity to maintain the equipment and machine systems always remain consistent in the production process. In general, maintenance problems are often neglected so that maintenance activities are not organized,
\end{abstract}


which in the end if the machine and equipment are damaged can affect production capacity. Required planned engine maintenance planning (preventive maintenance) in this case the replacement of preventive (preventive replacement) engine components to reduce engine damage suddenly (failure maintenance). PT. Pertamina EP Asset 3 Tambun Field is one of the companies engaged in the oil industry. PT. Pertamina EP Asset 3 Tambun Field has two components that are often damaged, resulting in a disrupted process. The two components are components of the Gas Compressor, the Connecting Rods and Crankcase components. The purpose of this study was to determine the critical components of the Gas Compressor at PT. Pertamina EP Asset 3 Tambun Field, determine preventive maintenance intervals for critical components using the Age replacement method.

Keyword : Age Replacement, Failure maintenance, Gas Compressor, Maintenance, Preventive maintenance.

\section{A. PENDAHULUAN}

Pemeliharaan (maintenance) merupakan aktivitas menjaga sistem peralatan dan mesin selalu tetap konsisten dalam proses produksi. Secara umum, masalah pemeliharaan sering terabaikan sehingga kegiatan pemeliharaan tidak teratur, yang pada akhirnya apabila mesin dan peralatan mengalami kerusakan dapat mempengaruhi kapasitas produksi. Dengan demikian, kegiatan pemeliharaan harus dilakukan secara tepat dan konsisten.

Diperlukan perencanaan perawatan mesin yang terjadwal (preventive maintenance) dalam hal ini penggantian pencegahan (preventive replacement) komponen mesin untuk mengurangi kerusakan mesin secara mendadak (failure maintenance). Maka perlu adanya penentuan interval penggantian komponen mesin. Sehingga dapat menekan downtime (waktu menganggur) yang ditimbulkan (Santoso, 2005). Maintenance atau perawatan mempunyai peran yang sangat menentukan dalam kegiatan produksi suatu perusahaan, karena aktivitas perawatan akan menentukan tingkat kelancaran dan efisiensi produksi. Dengan adanya kegiatan perawatan alat-alat produksi yang dilakukan oleh perusahaan secara rutin diharapkan alat-alat produksi tersebut dapat beroperasi dengan baik. Sehingga, dalam kegiatan produksi dan pengendalian kualitas produk dalam perusahaan dapat dilaksanakan dengan lebih baik. Alat-alat produksi yang selalu dalam keadaan baik diharapkan akan dapat meminimalkan jumlah produk cacat dan kualitas produk akhir dapat meningkat.

PT. Pertamina EP Asset 3 Tambun Field merupakan perusahaan yang bergerak di sektor hulu minyak dan gas bumi nasional. 
PT. Pertamina EP Asset 3 Tambun Field ini bertugas untuk mengelolah penambangan minyak dan gas bumi di Indonesia. Gas bumi yang dihasilkan dari sumur-sumur masih mengandung fraksi-fraksi hidrokarbon berat (C5H12-C7H16) atau biasa dikenal kondensat. Sehingga kondesat tersebut ditrap di PT. Pertamina EP Asset 3 Tambun Field. Umumnya sebelum ditrap kondensat tersebut, gas tersebut harus mempunyai tekanan yang tinggi. Sehingga gas tersebut harus dinaikan tekanannya.

Alat untuk menaikkan tekanan pada suatu gas adalah kompresor. Kompresor merupakan alat mekanik yang berfungsi untuk meningkatkan tekanan fluida. PT. Pertamina EP Asset 3 Tambun Field memiliki 6 (enam) Unit Gas Compresor yaitu Unit A,B,C,D,E dan G. Dari 6 Gas Compresor tersebut sering mengalami kendala diantaranya yaitu Gas Compresor shutdown dengan sendirinya. Hal ini tentunya akan sangat mempengaruhi output produksi yang di akibatkan oleh kendala yang terjadi pada Gas Compresor tersebut sehingga terjadi ketidaksesuaian antara target yang di inginkan perusahaan dengan aktual dilapangan. Oleh karena itu perlu dilakukan analisa apa penyebab dari kendala tersebut dan melakukan penjadwalan perawatan serta penjadwalan penggantian komponen agar gas engine selalu dalam keadaan baik.
Berdasarkan latar belakang yang telah diuraikan, maka dapat diambil beberapa masalah yang timbul dari penelitian ini adalah Tingginya kerusakan pada Gas Compresor unit CWaukesha L7042 GSI unit $\mathrm{C}$ sehingga perlu diketahui komponen apa saja yang mengalami kerusakan dan perlu dianalisis faktor - faktor apa saja yang menjadi penyebab kerusakan Gas Compresor Waukesha L7042 GSI serta membuat usulan tindakan agar bisa menurunkan downtime Gas Compresor tersebut. Tujuan dilakukannya penelitian ini adalah menentukan komponen kritis pada Gas Compressor dan menentukan interval waktu preventive maintenance dari komponen kritis.

\section{B. LANDASAN TEORI}

Perawatan adalah suatu kegiatan untuk merawat atau menjaga fasilitas/peralatan pabrik dan mengadakan perbaikan atau penyesuaian dan penggantian yang diperlukan agar terdapat suatu keadaan produksi yang memuaskan sesuai dengan apa yang direncanakan (Assauri, 2008 : 134)

Terdapat dua jenis perawatan, yaitu Preventive Maintenance dan Corrective Maintenance. Preventive maintenance adalah kegiatan perawatann dan pemeliharaan yang dilakukan untuk mencegah timbulnya kegagalan yang tidak terduga dan menemukan kondisi atau keadaan yang dapat menyebabkan 
fasilitas produksi mengalami kerusakan pada waktu proses produksi. (Assauri, 2008 : 135). Corective Maintenance adalah kegiatan perawatan atau peralatan yang dilakukan setelah terjadi suatu kerusakan/kelainan pada fasilitas atau peralatan sehingga tidak dapat berfungsi dengan baik. Maintenance dilakukan untuk mengurangi terjadi nya failure (kegagalan) pada mesin/komponen. Mesin atau peralatan dikatakan rusak apabila mesin atau peralatan tersebut tidak dapat dijalankan sesuai dengan fungsinya secara baik dan lancar. Kerusakan dari mesin atau peralatan tersebut salah satunya disebabkan oleh adanya human error dimana mesin tersebut tidak dijalankan sesuai dengan standar mesin tersebut.

Keandalan (reliability) suatu sistem/peralatan tergantung pada faktor eksternal dan tidak hanya dari kualitas produk itu sendiri (Ebeling,1997). Keandalan dari suatu sistem dapat dikatakan merupakan probabilitas sistem yang dapat berjalan dengan baik untuk melakukan tugas tertentu. Nilai keandalan berkisar antara 0 dan 1 .

Mean time to failure (MTTF) hanya digunakan pada komponen atau alat yang sering sekali mengalami kerusakan. Mean time to repair (MTTR) adalah rata - rata waktu komponen untuk dilakukan perawatan (repair). MTTR didasarkan atas lamanya perbaikan komponen yang mengalami kerusakan (failure) (Ansori, 2013:23).

Model age replacement adalah suatu model penggantian dimana interval waktu penggantian komponen dilakukan dengan memperhatikan umur pemakaian dari komponen tersebut, sehingga dapat menghindari terjadi penggantian peralatan yang masih baru dipasang akan ganti dalam waktu yang relatif singkat(Ansori, 2013:146).

Model Age Replacement terdapat dua siklus operasi yaitu :

a) Siklus I adalah siklus pencegahan yang diakhiri dengan kegiatan pencegahan dengan melakukan penggantian komponen yang telah mencapai umur penggantian umur penggantian sesuai dengan yang direncanakan.

b) Siklus II adalah siklus kerusakan yang diakhiri dengan kegiatan penggantian kerusakan sebelum mencapai waktu yang ditetapkan.

Model untuk masalah penentuan interval waktu yang optimal bagi penggantian pencegahan yang umum digunakan adalah model Age Replacement. Ekspektasi ongkos perawatan selama satu siklus penggantian pencegahan $t_{p}=$ ekspektasi ongkos penggantian pencegahan selama $t_{p}+$ ekspektasi ongkos penggantian kerusakan selama $t_{p}$. (Ansori,2013:147)

Pada dasarnya downtime didefinisikan sebagai waktu suatu 
komponen sistem tidak dapat digunakan tidak berada dalam kondisi yang baik, sehingga membuat fungsi sistem tidak berjalan. Berdasarkan kenyataan bahwa pada dasarnya prinsip utama dalam manajemen perawatan adalah untuk menekan periode kerusakan sampai batas minimum, maka keputusan penggantian komponen sistem berdasarkan downtime minimum menjadi sangat penting. Pembahasan berikut akan difokuskan pada proses pembuatan keputusan (R.Manzini,2010)

\section{METODE PENELITIAN}

Penelitian ini dilakukan di PT. Pertamina EP Asset 3 Tambun Field pada komponen Gas Compressor. Data yang digunakan adalah data kerusakan pada bulan Maret 2017 - Agustus 2017, Biaya akibat perawatan, dan data komponen kritis.

\section{Pengolahan Data}

Setelah data dikumpulkan maka langkah selanjutnya adalah pengolahan data. Berdasarkan pengumpulan data yang didapatkan maka dibuat pareto chart untuk mengidentifikasi komponen kritis pada PT. Pertamina EP Asset 3
Tambun Field. Kemudian dilakukan pengujian Distribusi untuk waktu antar kerusakan. Kemudian, mengidentifikasi penyebab kerusakan dengan menggunakan Fishbone.

Setelah dilakukan pengolahan data kemudian dilakukan usulan perbaikan dengan menggunakan metode $5 \mathrm{~W}+1 \mathrm{H}$ dan memberikan usulan penjadwalan pergantian komponen dengan Metode Age Replacement. Terakhir membuat kesimpulan dan saran.

\section{ANALISIS DATA DAN PEMBAHASAN}

\section{Penentuan Komponen Kritis}

Berdasarkan data kerusakan yang diperoleh, downtime gas compresor diurutkan mulai dari yang terbesar sampai terkecil, kemudian dibuatdan `dianalisis dengan diagram pareto untuk memudahkan pemilihan komponen kritis. Diagram pareto mengenai besarnya total downtime yang disebabkan oleh komponen gas compressor WaukeshaL7042 GSI. Berdasarkan data yang diperoleh, maka presentase downtime digambarkan pada Tabel 1 dan diagram pareto dapat dilihat pada Gambar 1 
Tabel 1. Persentase Downtime komponen gas compressor WaukeshaL7042 GSI periode Maret 2017 - Agustus 2017

\begin{tabular}{|c|r|r|r|r|}
\hline Komponen & Frekuensi Kerusakan & $\begin{array}{c}\text { Kumulatif } \\
\text { Frekuensi Kerusakan }\end{array}$ & Persen (\%) & Kumulatif Persen (\%) \\
\hline Crankcase & 7 & 7 & $58.33 \%$ & $58.33 \%$ \\
\hline Connecting Rods & 5 & 12 & $41.67 \%$ & $100 \%$ \\
\hline
\end{tabular}

Sumber :Pengumpulan Data (2018)

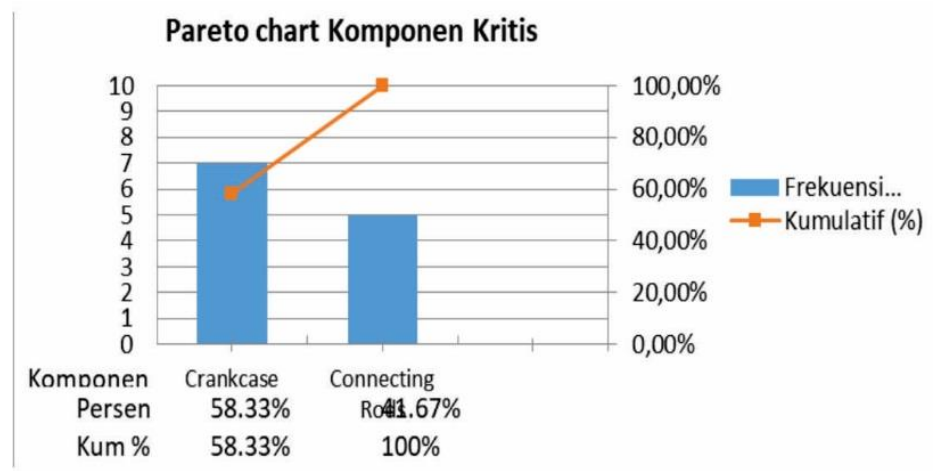

Sumber :Pengumpulan Data (2018)

Gambar 1. Diagram pareto komponen kritis gas engine caterpillar 3516

Berdasarkan Gambar 1. diagram pareto diatas diketahui bahwa $70 \%$ downtime gas compressor WaukeshaL7042 GSI disebabkan oleh dua komponen utama gas compressor WaukeshaL7042 GSI yang mengalami kerusakan dan memiliki downtime tinggi. Komponen tersebut ialah crankcase dan connecting rods.

\section{Pengujian Goodness of Fit}

\section{Komponen Crankcase}

Tabel 2 merupakan table perhitungan dari nilai TTF dan TTR dari komponen crankcase

Tabel 2 TTR dan TTF Komponen Crankcase

\begin{tabular}{|c|c|c|}
\hline Periode (i) & TTR (Xi) Jam & $\begin{array}{c}\text { TTF (Xi) } \\
\text { Jam }\end{array}$ \\
\hline 1 & 2.25 & 350.42 \\
\hline 2 & 2.15 & 360 \\
\hline 3 & 3.85 & 372.32 \\
\hline 4 & 1.95 & 320 \\
\hline 5 & 1.55 & 270 \\
\hline 6 & 0.74 & 262 \\
\hline
\end{tabular}

Sumber :Pengolahan Data (2018)

Setelah diketahui data time to failure (TTF) dan data time to repair (TTR) maka dilakukan uji distribusi dan hasil dari uji goodness of fit menggunakan software minitab 18 pada menu Stat>Quality Tools >Individual Distribution Identification. Dengan kriteria pemilihan adalah nilai statistik 
Anderson-Darling yang paling kecil.Berikut adalah hasil Descriptive Statistics dari uji goodness of fit menggunakan software minitab 18.

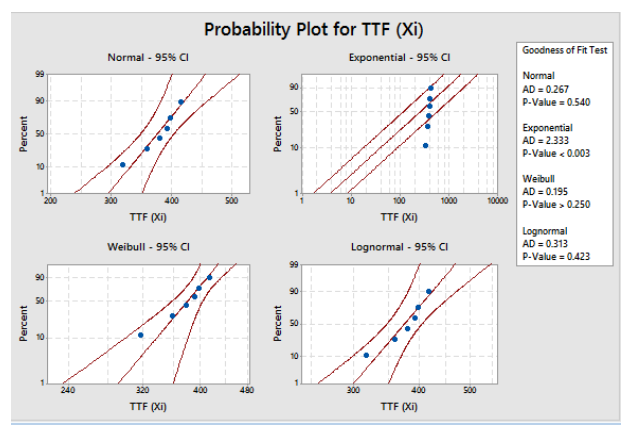

Sumber :Pengolahan Data (2018)

Gambar 2 Uji Goodness of Fit Komponen Crankcase

Penentuan distribusi waktu antar kerusakan dan waktu antar perbaikan ini menggunakan software minitab 18 , dimana dengan kriteria pemilihan adalah nilai statistik Anderson-Darling yang paling kecil. Setelah uji goodness of fit didapatkan hasil dari nilai waktu antar kerusakan (TTF) lebih kecil dibandingkan distribusi lain, yaitu berdistribusi Weibull dengan nilai statistik Anderson-Darling $\mathrm{AD}=0.195$ (TTF).

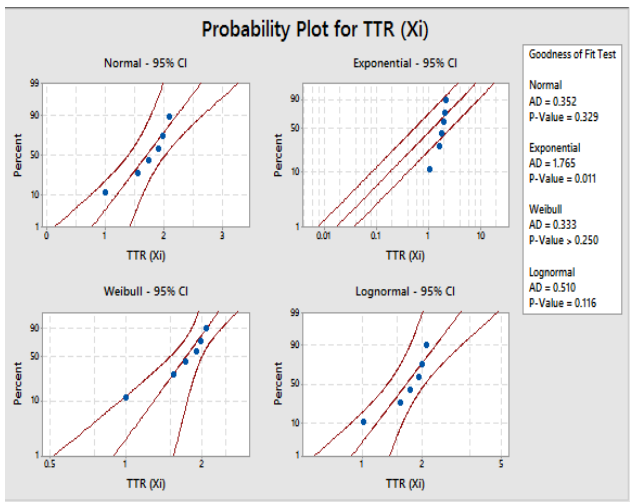

Sumber :Pengolahan Data (2018)

Gambar 3 Uji Goodness of Fit TTRKomponen Crankcase
Dari gambar 2 dan gambar 3 maka distribusi untuk TTF dan TTR untuk komponen crankcase adalah Distribusi Weibull.

\section{Komponen Connecting Rods}

Tabel 3 merupakan hasil perhitungan TTF dan TTR untuk komponen Connecting Rods

Tabel 3 TTR dan TTF Komponen Connecting Rods

\begin{tabular}{|c|c|c|}
\hline Periode (i) & $\begin{array}{c}\text { TTR (Xi) } \\
\text { Jam }\end{array}$ & $\begin{array}{c}\text { TTF (Xi) } \\
\text { Jam }\end{array}$ \\
\hline 1 & 1.5 & 320 \\
\hline 2 & 3.25 & 312.12 \\
\hline 3 & 1.3 & 253 \\
\hline 4 & 1.2 & 251 \\
\hline 5 & 0.5 & 232.10 \\
\hline 6 & 0.3 & 212.04 \\
\hline
\end{tabular}

Sumber :Pengolahan Data (2018)

Setelah diketahui data time to failure (TTF) dan data time to repair (TTR) maka dilakukan uji distribusi dan hasil dari uji goodness of fit menggunakan software minitab 18 pada menu Stat>Quality Tools >Individual Distribution Identification. Dengan kriteria pemilihan adalah nilai statistik Anderson-Darling yang paling kecil.Berikut adalah hasil Descriptive Statistics dari uji goodness of fit menggunakan software minitab 18.

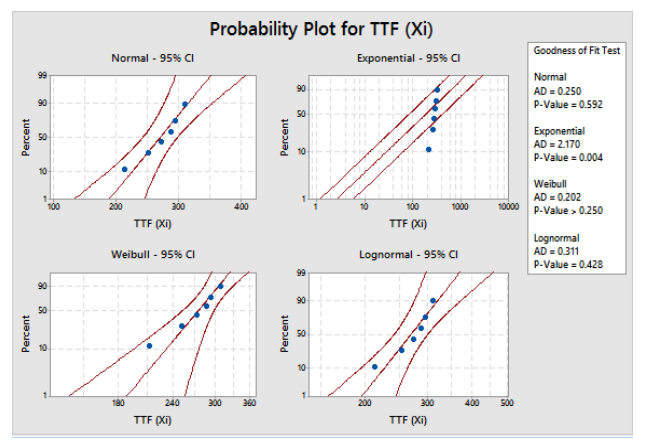

Sumber :Pengolahan Data (2018) 
Gambar 3 Uji Goodness of Fit Komponen Connecting Rods

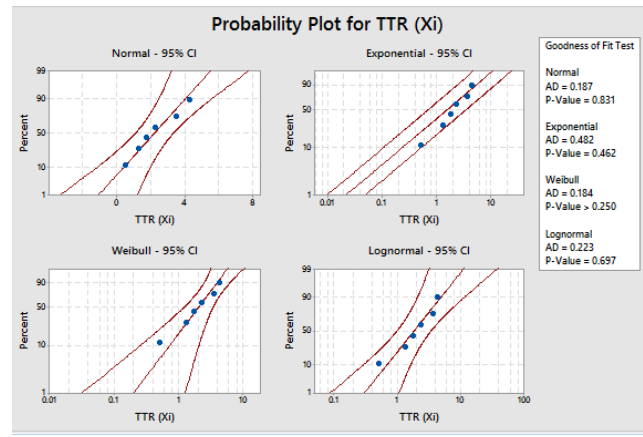

Sumber :Pengolahan Data (2018)

Gambar 4 Uji Goodness of Fit TTR Komponen Connecting Rods
Dari gambar 3 dan 4 dapat disimpulkan bahwa komponen connecting rods memiliki Distribusi Weibull untuk TTF dan TTR

\section{Perhitungan MTTF \\ Komponen Crankcase}

Setelah dilakukan penentuan distribusi dari masing-masing komponen. Langkah selanjutnya adalah perhitungan MTTF untuk masingmasing komponen. Tabel 4 merupakan tabel untuk perhitungan nilai $\beta$ dan $\theta$ untuk komponen crankcase

Tabel 4. Perhitungan $\beta$ dan $\theta$ DistribusiWeibull Time To Failure (TTF) KomponenCrankcase

\begin{tabular}{|c|c|c|c|c|c|c|c|}
\hline $\begin{array}{l}\text { Periode } \\
\text { (i) }\end{array}$ & $\begin{array}{l}\text { TTF } \\
\text { (Xi) }\end{array}$ & $\ln \mathrm{Xi}$ & $\begin{array}{c}f(\mathrm{ti})=(\mathrm{i}- \\
0.3 / \mathrm{n}+0.4)\end{array}$ & $\begin{array}{c}\mathrm{Yi}=\{\ln (\ln (1 / 1- \\
\mathrm{F}(\mathrm{ti})))\}\end{array}$ & Xi.Yi & $\mathrm{Xi}^{2}$ & $\mathrm{Yi}^{2}$ \\
\hline 1 & 350.42 & 5.859 & 0.109 & -2.156 & -12.6300 & 34.3294 & 4.64668 \\
\hline 2 & 360 & 5.886 & 0.265 & -1.175 & -6.9177 & 34.6462 & 1.38126 \\
\hline 3 & 372.32 & 5.919 & 0.421 & -0.602 & -3.5609 & 35.0434 & 0.36185 \\
\hline 4 & 320 & 5.768 & 0.578 & -0.147 & -0.8495 & 33.2735 & 0.02169 \\
\hline 5 & 270 & 5.598 & 0.734 & 0.282 & 1.57829 & 31.3423 & 0.07947 \\
\hline 6 & 262 & 5.568 & 0.890 & 0.794 & 4.4231 & 31.0064 & 0.630976 \\
\hline \multicolumn{2}{|c|}{ Total } & 34.600 & & -3.003 & -17.9569 & 199.6414 & 7.121942 \\
\hline
\end{tabular}

Sumber :Pengolahan Data (2018)

Perhitungan nilai parameter $\beta$ dan $\alpha$ sebagai berikut :

$$
\begin{aligned}
\beta=\mathrm{b} & =\frac{n * \Sigma X i Y i-\Sigma \ln X i * \Sigma Y i}{n * \Sigma X i^{2}-(\Sigma \ln X i)^{2}} \\
& =\frac{6 *(-17.965)-(34.600) *(-3.003)}{6 *(199.641)-(34.600)^{2}} \\
& =\frac{-107.79+103.903}{1197.864-1197.16}=\frac{3.886}{0.704} \\
& =5.51 \\
\alpha=\mathrm{a} & =\frac{\sum Y i-b * \Sigma X i}{n} \\
& =\frac{-3.003-(5.51 * 34.600)}{6} \\
& =\frac{-193.649}{6}=-32.27
\end{aligned}
$$

Penentuannilai $\theta$ sebagaiparameter :

$\Theta=\mathrm{e}^{\frac{-a}{\beta}}=\mathrm{e}^{\frac{-(-32 . Z)}{5.51}}=\mathrm{e}^{5.4}=559.72$
Perhitungan untuk data TTF komponen crangkcase mengikuti distribusi weibull. Nilai MTTF dihitung dengan rumus sebagai berikut :

MTTF =

$$
\begin{aligned}
\Theta\left(1+\frac{1}{\beta}\right)=559.72\left(1+\frac{1}{5.51}\right) \\
=559,72(1.18) \text { Tabel gamma } \\
=559,72(0.92373) \\
=517.03 \mathrm{Jam}
\end{aligned}
$$




\section{Komponen Connecting Rods}

Selanjutnya adalah menghitung nilai MTTF untuk komponen Connecting Rods. Perhitungan nilai parameter $\beta$ dan $\alpha$ sebagai berikut

$$
\begin{aligned}
\beta=\mathrm{b} & =\frac{n * \Sigma X i Y i-\Sigma \ln X i * \Sigma Y i}{n * \Sigma X i^{2}-(\Sigma \ln X i)^{2}} \\
& =\frac{6 *(-17.535)-(33.374) *(-3.003)}{6 *(185.775)-(33.374)^{2}} \\
& =\frac{-105.21+100.22}{1114.65-1113.82}=\frac{4.98}{0.82} \\
& =6.07 \\
\alpha=\mathrm{a} & =\frac{\Sigma Y i-b * \Sigma X i}{n} \\
& =\frac{-3.003-(6.07 * 33.3 / 4)}{6} \\
& =\frac{-205.58}{6}=-34.26
\end{aligned}
$$

Penentuannilai $\theta$ sebagaiparameter :

$$
\Theta=\mathrm{e}^{\frac{-a}{\beta}}=\mathrm{e} \frac{-(-34.26)}{6.07}=\mathrm{e}^{5.6}=270.42
$$

Perhitungan untuk data TTF komponen connecting rods mengikuti distribusi weibull. Nilai MTTF dihitung dengan rumus sebagai berikut :

$$
\begin{aligned}
& \text { MTTF } \\
& \begin{aligned}
& \Theta\left(1+\frac{1}{\beta}\right)=270.42\left(1+\frac{1}{6.07}\right) \\
&=270,42(1.16) \text { Tabel gamma } \\
&=270,42(0.92980) \\
&=251.43 \mathrm{Jam}
\end{aligned}
\end{aligned}
$$

\section{Perhitungan MTTR}

\section{Komponen Crankcase}

Setelah dilakukan uji Goodness OfFit, perhitungan selanjutnya yaitu perhitungan parameter time to repair (TTR). Perhitungantime to repair (TTR).komponen Crankcase dapat dilihat pada Tabel 6. Perhitungan nilai parameter $\beta$ dan $\alpha$ sebagai berikut :

$$
\begin{aligned}
\beta= & \mathrm{b}=\frac{n * \Sigma X i Y i-\Sigma \ln X i * \Sigma Y i}{n * \sum X i^{2}-\left(\sum \ln X i\right)^{2}} \\
= & \frac{6 *(3.672)-(3.729) *(-3.003)}{6 * 3.789-(3.729)^{2}} \\
= & \frac{22.032+11.198}{22.734-13.905}=\frac{33.384}{8.828} \\
= & 3.78 \\
\alpha=\mathrm{a}= & \frac{\Sigma Y i-b * \Sigma X i}{n} \\
= & \frac{(-3.003)-(4.91 * 3.729)}{6}= \\
\frac{(-3.003)-14.095}{6} & \frac{-17.09}{6}=-2.84
\end{aligned}
$$

Penentuannilai $\theta$ sebagaiparameter :

$\Theta=\mathrm{e}^{\frac{-\mathrm{a}}{\beta}}=\mathrm{e} \frac{-(-2.84)}{3.78}=2.11$

Perhitungan untuk data TTR komponen Crankcasemengikuti distribusi weibull. Nilai MTTR dihitung dengan rumus sebagai berikut :

MTTR $=$ ӨГ $\left(1+\frac{1}{\beta}\right)=2.11(1+$ $\left.\frac{1}{3.78}\right)$

$$
\begin{aligned}
& =2.11(1.26) \text { Tabel Gamma } \\
& =2.11(0.90440) \\
& =1.90 \mathrm{Jam}
\end{aligned}
$$

\section{Komponen Connecting Rods}

Setelah dilakukan uji Goodness OfFit, perhitungan selanjutnya yaitu perhitungan parameter time to repair (TTR). Perhitungantime to repair (TTR).komponen Crankcase dapat dilihat pada Tabel 7. Perhitungan nilai parameter $\beta$ dan $\alpha$ sebagai berikut :

$$
\begin{aligned}
& \beta=b=\frac{n \sum X i Y i-\sum \ln X i Y i}{n \sum X i^{2}-\left(\sum \ln X i\right)^{2}} \\
& =\frac{6(-3.595)-(0.131)(-3.003)}{6(3.585)-(0.131)^{2}} \\
& =\frac{21.117}{20.508}=1,02
\end{aligned}
$$




$$
\begin{aligned}
& \alpha=a=\frac{\sum Y i-b \sum X i}{n} \\
& =\frac{(-3.003)-(1,02 \times 0.131)}{6}=-0,52
\end{aligned}
$$

Penentuan nilai $\theta$ sebagai parameter

$$
\theta=e^{\frac{-\alpha}{\beta}}=e^{\frac{-(-0,52)}{1,02}}=1,66
$$

Perhitungan untuk data TTR komponen Crankcase mengikuti distribusi weibull. Nilai MTTR dihitung dengan rumus sebagai berikut :

$$
\begin{aligned}
& \text { MTTR }=\text { ӨГ }\left(1+\frac{1}{\beta}\right)=1.66\left(1+\frac{1}{1.02}\right) \\
& =1.66(1.98) \text { Tabel Gamma } \\
& =1.66(0.99171) \\
& =1.64 \mathrm{Jam}
\end{aligned}
$$

\section{Penentuan Nilai Interval Waktu Pergantian \\ Komponen Crankcase}

Setelah mendapatkan nilai MTTF dan MTTR untuk komponen crankcase selanjutnya adalah menentukan interval waktu pergantian komponen.

Hasil dari penentuan interval komponen dapat dilihat pada Tabel 8

Contoh Perhitungan jika tp $=100$

$\mathrm{MTTF}=517.03$

$$
\begin{array}{ll}
\mathrm{F}(\mathrm{t}) & =1-e^{-\lambda t} \\
\mathrm{~F}(100) & =1-e^{-100 / 517.03} \\
\mathrm{~F}(\mathrm{t}) & =0,17585 \\
\mathrm{R}(\mathrm{t}) & =1-\mathrm{F}(\mathrm{t}) \\
\mathrm{R}(100) & =1-0,17585=0,82414 \\
\mathrm{M}(\mathrm{tp}) & =\frac{M T T F}{F(t p)} \\
\mathrm{M}(\mathrm{tp}) & =\frac{517.03}{0,17585}
\end{array}
$$

$\mathrm{M}(\mathrm{tp})=2940,1762$

$$
D(t p)=\frac{T f \cdot R(t p)+T f(1-R(t p))}{(t p+T p) \cdot R(t p)+(M(t p)+T f(1-(R(t p)}
$$

$D(t p)=\frac{(11,32)(0,82414)+11,32(1-0,82414)}{(100+11,32)^{*} 0,82414+(2940,1762+11,32)(1-0,82414)}$

$\mathrm{D}(\mathrm{tp}) \quad=0,00647879$

Berdasarkan Tabel 8, diperoleh hasil nilai $T$ minimum yaitu :

$T=$ Age Replacement $=1200 \mathrm{Jam}$

\section{Komponen Connecting Rods}

Setelah mendapatkan nilai MTTF dan MTTR untuk komponen crankcase selanjutnya adalah menentukan interval waktu pergantian komponen.

Hasil dari penentuan interval komponen dapat dilihat pada Tabel 9

\section{Usulan Penjadwalan \\ Penggantian Komponen}

Pada pembahasan sebelumnya sudah dihitungan total minimum downtim $e$ atau nilai $T=$ (age replacement) pada tiap-tiap komponen gas compressor waukesha L7042 GSI. Pada Tabel 10 dapat dilihat hasil pemilihan waktu penjadwalan pergantian untuk masing-masing komponen. 
Tabel 5 Perhitungan $\beta$ dan $\theta$ DistribusiWeibull Time ToFailure(TTF) KomponenConeccting Rods

\begin{tabular}{|c|c|c|c|c|c|c|c|}
\hline $\begin{array}{l}\text { Periode } \\
\text { (i) }\end{array}$ & $\begin{array}{l}\text { TTF } \\
\text { (Xi) }\end{array}$ & $\ln \mathrm{Xi}$ & $\begin{array}{c}\mathrm{f}(\mathrm{ti})=(\mathrm{i}- \\
0.3 / \mathrm{n}+0.4)\end{array}$ & $\begin{array}{c}\mathrm{Yi}=\{\ln (\ln (1 / 1- \\
\mathrm{F}(\mathrm{ti})))\}\end{array}$ & Xi.Yi & $\mathrm{Xi}^{2}$ & $\mathrm{Yi}^{2}$ \\
\hline 1 & 320 & 5.76832 & 0.109375 & -2.156 & -12.4342 & 33.2735 & 4.6466 \\
\hline 2 & 312.12 & 5.74338 & 0.265625 & -1.175 & -6.7500 & 32.9865 & 1.3812 \\
\hline 3 & 253 & 5.53338 & 0.421875 & -0.602 & -3.3285 & 30.6183 & 0.3618 \\
\hline 4 & 251 & 5.52545 & 0.578125 & -0.147 & -0.81382 & 30.5306 & 0.0216 \\
\hline 5 & 232.1 & 5.44716 & 0.734375 & 0.282 & 1.53565 & 29.6716 & 0.0794 \\
\hline 6 & 212.04 & 5.35677 & 0.890625 & 0.794 & 4.25510 & 28.6950 & 0.6309 \\
\hline \multicolumn{2}{|c|}{ Total } & 33.37449 & & -3.003 & -17.5359 & 185.7757 & 7.1219 \\
\hline
\end{tabular}

Sumber :Pengolahan Data (2018)

Tabel 6 Perhitungan $\beta$ dan $\theta$ DistribusiWeibull Time To repair (TTR) Komponen Crankcase

\begin{tabular}{|c|c|c|c|c|c|c|c|}
\hline $\begin{array}{c}\text { Periode } \\
(\mathrm{i})\end{array}$ & $\begin{array}{c}\mathrm{TTR} \\
(\mathrm{Xi})\end{array}$ & $\ln \mathrm{Xi}$ & $\begin{array}{c}\mathrm{f}(\mathrm{ti})=(\mathrm{i}- \\
0.3 / \mathrm{n}+0.4)\end{array}$ & $\begin{array}{c}\mathrm{Yi}=\{\ln (\ln (1 / 1 \\
-\mathrm{F}(\mathrm{ti})))\}\end{array}$ & $\mathrm{Xi} . \mathrm{Yi}$ & $\mathrm{Xi}^{2}$ & $\mathrm{Yi}^{2}$ \\
\hline 1 & 2.25 & 0.8109 & 0.1093 & -2.156 & -1.74805 & 0.65760 & 4.6466 \\
\hline 2 & 2.15 & 0.7654 & 0.2656 & -1.175 & -0.89963 & 0.58594 & 1.3812 \\
\hline 3 & 3.85 & 1.3480 & 0.4218 & -0.602 & -0.81092 & 1.81730 & 0.3618 \\
\hline 4 & 1.95 & 0.6678 & 0.5781 & -0.147 & -0.09836 & 0.44599 & 0.0216 \\
\hline 5 & 1.55 & 0.4382 & 0.7343 & 0.282 & 0.12355 & 0.19206 & 0.0794 \\
\hline 6 & 0.74 & -0.3011 & 0.8906 & 0.794 & -0.23917 & 0.09066 & 0.6309 \\
\hline \multicolumn{2}{|c|}{ Total } & 3.7294 & & -3.003 & -3.67260 & 3.78957 & 7.1219 \\
\hline
\end{tabular}

Sumber :Pengolahan Data (2018)

Tabel 7 Perhitungan $\beta$ dan $\theta$ DistribusiWeibull Time To repair (TTR) KomponenConecting Rods

\begin{tabular}{|c|c|c|c|c|c|c|c|}
\hline $\begin{array}{l}\text { Periode } \\
\text { (i) }\end{array}$ & TTR (Xi) & $\ln \mathrm{Xi}$ & $\begin{array}{c}\mathrm{f}(\mathrm{ti})=(\mathrm{i}- \\
0.3 / \mathrm{n}+0.4)\end{array}$ & $\begin{array}{c}\mathrm{Yi}=\{\ln (\ln (1 / 1- \\
\mathrm{F}(\mathrm{ti})))\}\end{array}$ & Xi.Yi & $\mathrm{Xi}^{2}$ & $\mathrm{Yi}^{2}$ \\
\hline 1 & 1.5 & 0.4054 & 0.109375 & -2.156 & -0.87402 & 0.1644 & 4.64668 \\
\hline 2 & 3.25 & 1.1786 & 0.265625 & -1.175 & -1.38523 & 1.3892 & 1.38126 \\
\hline 3 & 1.3 & 0.2623 & 0.421875 & -0.602 & -0.15782 & 0.0688 & 0.36185 \\
\hline 4 & 1.2 & 0.1823 & 0.578125 & -0.147 & -0.02685 & 0.0332 & 0.02169 \\
\hline 5 & 0.5 & -0.6931 & 0.734375 & 0.282 & -0.19541 & 0.4804 & 0.07947 \\
\hline 6 & 0.3 & -1.2039 & 0.890625 & 0.794 & -0.95636 & 1.4495 & 0.63097 \\
\hline \multicolumn{2}{|c|}{ Total } & 0.1316 & & -3.003 & -3.59571 & 3.5857 & 7.12194 \\
\hline
\end{tabular}


Tabel 8.Penentuan Nilai Interval Waktu Penggantian Komponen Crankcase

\begin{tabular}{|c|c|c|c|c|}
\hline tp (jam) & $\mathbf{F ~ ( t p ) ~}$ & $\mathbf{R}(\mathbf{t p )}$ & $\mathbf{M}$ (tp) & $\mathbf{D}$ (tp) \\
\hline 100 & 0.17585 & 0.82415 & 2940.176 & 0.00647879 \\
\hline 200 & 0.32065 & 0.67935 & 1612.443 & 0.01001264 \\
\hline 300 & 0.44006 & 0.55994 & 1174.908 & 0.01146012 \\
\hline 400 & 0.53848 & 0.46152 & 960.1657 & 0.01168603 \\
\hline 500 & 0.6196 & 0.3804 & 834.4577 & 0.01129561 \\
\hline 600 & 0.68647 & 0.31353 & 753.172 & 0.01064219 \\
\hline 700 & 0.74158 & 0.25842 & 697.2006 & 0.00991143 \\
\hline 800 & 0.787 & 0.213 & 656.9632 & 0.00919301 \\
\hline 900 & 0.82444 & 0.17556 & 627.1287 & 0.00852568 \\
\hline 1000 & 0.8553 & 0.1447 & 604.5013 & 0.00792257 \\
\hline 1100 & 0.88073 & 0.11927 & 587.0471 & 0.00738460 \\
\hline $\mathbf{1 2 0 0}$ & $\mathbf{0 . 9 0 1 7}$ & $\mathbf{0 . 0 8 3 0}$ & $\mathbf{5 7 0 . 3 9 4 7}$ & $\mathbf{0 . 0 0 6 8 3 0 8 9}$ \\
\hline 1300 & 0.91897 & 0.0983 & 573.3947 & 0.00690723 \\
\hline 1400 & 0.93322 & 0.06678 & 554.028 & 0.00610831 \\
\hline 1500 & 0.94495 & 0.05505 & 547.1506 & 0.00577362 \\
\hline 1600 & 0.95463 & 0.04537 & 541.6025 & 0.00545580 \\
\hline
\end{tabular}

Sumber :Pengolahan Data (2018)

Tabel 9.Penentuan Nilai Interval Waktu Penggantian Komponen Conecting Rods

\begin{tabular}{|c|c|c|c|c|}
\hline tp (jam) & $\mathbf{F ~ ( t p ) ~}$ & $\mathbf{R}$ (tp) & M (tp) & D (tp) \\
\hline 100 & 0.32815 & 0.67185 & 766.2045 & 0.00615388 \\
\hline 200 & 0.54862 & 0.45138 & 458.2954 & 0.00722096 \\
\hline 300 & 0.6967 & 0.3033 & 360.887 & 0.00661609 \\
\hline 400 & 0.79625 & 0.20375 & 315.7677 & 0.00575320 \\
\hline 500 & 0.86311 & 0.13689 & 291.307 & 0.00498857 \\
\hline 600 & 0.90803 & 0.09197 & 276.8961 & 0.00437134 \\
\hline 700 & 0.93821 & 0.06179 & 267.989 & 0.00388086 \\
\hline 800 & 0.95848 & 0.04152 & 262.3216 & 0.00348801 \\
\hline 900 & 0.97211 & 0.02789 & 258.6436 & 0.00316846 \\
\hline 1000 & 0.98126 & 0.01874 & 256.2318 & 0.00290414 \\
\hline 1100 & 0.98741 & 0.01259 & 254.6359 & 0.00268196 \\
\hline 1200 & 0.99154 & 0.00846 & 253.5752 & 0.00249249 \\
\hline $\mathbf{1 3 0 0}$ & $\mathbf{0 . 9 9 4 3 1}$ & $\mathbf{0 . 0 0 5 6 9}$ & $\mathbf{2 5 2 . 8 6 8 8}$ & $\mathbf{0 . 0 0 2 3 2 8 8 5}$ \\
\hline 1400 & 0.99168 & 0.00832 & 253.5394 & 0.00249151 \\
\hline 1500 & 0.99743 & 0.00257 & 252.0778 & 0.00205998 \\
\hline 1600 & 0.99827 & 0.00173 & 251.8657 & 0.00194802 \\
\hline
\end{tabular}


Tabel 10 Usulan Jadwal Penggantian Komponen Gas Compresor Waukesha L7042 GSI dengan Metode Age Replacement

\begin{tabular}{|c|c|c|c|}
\hline No. & Komponen & Nilai & Nilai \\
& & T= (Age Replacement) & D (tp) $\min$ \\
\hline 1. & Crankcase & 1200 Jam & $\mathbf{0 . 0 0 6 8 3 0 8 9}$ \\
\hline 2. & Conecting Rods & 1300 Jam & $\mathbf{0 . 0 0 2 3 2 8 8 5}$ \\
\hline
\end{tabular}

Sumber :Pengolahan Data (2018)

\section{E. KESIMPULAN DAN SARAN}

\section{Kesimpulan}

Berdasarkan hasil penelitian yang telah dilakukan dan diuraikan maka dapat diperoleh kesimpulan sebagai berikut :

1. Komponen yang paling sering rusak padagas compressor waukesha L7042 GSI dilihat dari tingkat frekuensi tertinggi pada periode Maret 2017 - Agustus 2017 adalah komponen Crankcase dengan jumlah kerusakan tujuh kali dan komponen Conecting Rods mengalami lima kali kerusakan.

2. Usulan tindakan perbaikan pada gas compressor waukesha L7042 GSI adalah dengan melakukan tindakan preventive maintenance dengan waktu pergantian komponen crankcase setiap1200 jam dengan nilai $\mathrm{D}(t p)_{\min }=$ 0.00683089, dan komponen connecting rods setiap 1300 jam dengan nilai $\mathrm{D}(t p)_{\min }=$ 0.00232885

\section{Saran}

Dari kesimpulan di atas, beberapa saran yang disampaikan dalam penelitian ini guna proses produksi berjalan dengan optimal adalah sebagai berikut :

1. Membuat jadwal perawatan dan jadwal penggantian komponen gas compressor waukesha L7042 GSI serta melakukan pengecekan setiap waktu agar kondisi gas compressor tetap terjaga dan gas compressor mampu beroperasi dengan baik dengan tujuan meningkatkan output produksi.

2. Memberikan pelatihan (training) perawatan yang bersifatahli agar para teknisi mampu memahami peran dan fungsi perawatan demi terealisasinya spesialis gas compresor.

3. Bagi penelitian selanjutnya, disarankan lebih banyak komponen yang diteliti, sehingga dapat semakin meminimalisir terjadinya kegagalan. 


\section{DAFTAR PUSTAKA}

Ansori, Nachnul. 2013, Sistem Perawatan Terpadu, Jawa Timur.

Assauri, Sofjan. 2008. Manajemen Produksi dan Operasi. Lembaga Penerbitan Fakultas Ekonomi Universitas Indonesia. Jakarta.

Corder, S. Antony. 2000. Teknik Manajemen Pemeliharaan. Jakarta : Erlangga.

Ebeling, E, C. 1997, An Introduction to Reliablity and Maintanability Engineering, Mc Graw-Hill, Singapore.

Gasper, K., \& Clore, G. L. 2002. Attending to the Big Picture Mood and Global versus Local Processing of Visual Information. Psychological Science

Jaka Purnama,Yosua Anggara Putra, Moch. Kalamollah. 2015. Metode Age Replacement Digunakan Untuk Menentukan Interval Waktu Perawatan Mesin Pada Armada Bus. Surabaya : Institut Teknologi Adhi Tama.

Juliandi Wirawan Krisnadi,

Kusmaningrum Soemadi, Fifi Herni Mustofa. 2014. Optimasi Waktu Penggantian Komponen Pada Lokomotif DE CC 201 Seri 99 Menggunakan Metoda Age Replacement di PT. Kereta Api Indonesia. Bandung :
Institut Teknologi Nasional (ITENAS).

Lewit, dan Joel. 2003. Complete Guide to Preventive Predictive Maintenance. Industrial Press, USA

R. Manzini, et al. Maintenance for Industrial Systems London: Springer, 2010, h.355-358 Universitas Sumatera Utara

Setiawan, F.D. 2008. Perawatan Mekanikal Mesin Produksi. Yogyakarta : Maximus

Zhona Muhamad Adinata Pratama. 2018. Usulan Penjadwalan Penggantian Komponen Pada Mesin Rolling dan Heading di PT DRA COMPONENT PERSADA Dengan Metode Age Replacement.Jakarta : Universitas Pancasila. 